Jurnal Magisma Vol. 6 No. 1 - Tahun 2018

\title{
PENGARUH SUPERVISI BIDAN KOORDINATOR TERHADAP STANDAR MUTU PELAYANAN ANTENATAL CARE DENGAN MOTIVASI KERJA SEBAGAI VARIABEL INTERVENING PADA BIDAN DI WILAYAH PUSKESMAS PAGIYANTEN KABUPATEN TEGAL
}

\author{
Siti Aminah \\ STIKES KEMENKES SEMARANG \\ siti4mienah@gmail.com
}

\begin{abstract}
Angka Kematian Ibu (AKI) Kabupaten Tegal tahun 2016 sebesar 112 per 100.000 kelahiran hidup dan tahun 2017 menjadi 52,7 per 100.000 kelahiran hidup, pelayanan antenantal merupakan pelayanan yang diberikan terhadap ibu hamil oleh petugas kesehatan untuk memelihara kehamilannya yang dilakukan sesuai standar pelayanan antenantal yang ditetapkan dalam standar pelayanan kebidanan termasuk ANC yang dilakukan dengan supervisi bidan koordinator dan motivasi kerja. Tujuan penelitian ini memperoleh bukti empiris mengenai pengaruh supervisi bidan koordinator terhadap standar mutu pelayanan antenatal care dengan motivasi kerja sebagai variabel intervening pada bidan di Wilayah Puskesmas Pagiyanten Kabupaten Tegal.

Populasi dari penelitian ini adalah bidan yang bekerja dan berdomisi di wilayah puskesmas Pagiyanten yang berjumlah 48 orang, sampel penelitian adalah menggunakan teknik total sampling pada seluruh populasi penelitian. Pengumpulan data menggunakan kuesioner, teknik analisis data menggunakan regresi linier berganda dan analisis path.

Hasil Penelitian menunjukkan bahwa supervisi bidan koordinator mempunyai pengaruh positif terhadap standar mutu pelayanan ANC pada bidan, supervisi bidan koordinator mempunyai pengaruh terhadap motivasi kerja pada bidan, motivasi kerja mempunyai pengaruh yang positif terhadap mutu pelayanan ANC pada bidan. Kesimpulan terdapat tidak terdapat pengaruh supervisi bidan koordinator terhadap standar mutu pelayanan antenatal care dengan motivasi sebagai variabel intervening pada bidan di Wilayah Puskesmas Pagiyanten Kabupaten Tegal. Saran bagi pemangku kebijakan kesehatan ibu dan anak, bahwa dalam rangka menciptakan mutu pelayanan ANC maka harus mengaplikasikan supervisi bidan koordinator secara berkala dan terjadwal dan meningkatkan standar mutu supervisi bidan koordinator.
\end{abstract}

Kata Kunci: supervisi bidan koordinator, standar mutu pelayanan antenatal care, motivasi kerja

\section{Pendahuluan}

Angka kematian ibu (AKI), Angka Kematian Neonatus (AKN), Angka Kematian Bayi (AKB), Angka Kematian Balita (AKBA), merupakan beberapa indikator status kesehatan masyarakat. AKI dan AKB di Indonesia masih tinggi di banding dengan Negara ASEAN lainnya. Menurut data Survei Demokrasi Kesehatan Indonesia (SDKI) 2012, AKI 359 per 100.000 kelahiran hidup, AKB 24 per 1.000 kelahiran hidup sedangkan Menurut laporan WHO tahun 2014 Angka Kematian Ibu (AKI) di Indonesia yaitu 214 per 100.000 kelahiran hidup, AKI Kabupaten Tegal tahun 2016 sebesar 112 per 100.000 kelahiran hidup dan tahun 2017 menjadi 52,7 per 100.000 kelahiran hidup (Depkes RI, 2016).

Tingginya Angka Kematian Ibu (AKI) antara lain disebabkan oleh pelayanan pemeriksaan kehamilan dan pertolongan persalinan oleh tenaga profesional belum sepenuhnya dimanfaatkan oleh masyarakat, sehingga menyebabkan masih banyak ibu tidak memeriksakan kehamilannya dan banyak ibu tidak menerima pemeriksaan kehamilan sesuai dengan standar program kesehatan ibu dan anak (Ridwan, 2007).

Pelayanan antenatal merupakan pelayanan yang diberikan terhadap ibu hamil oleh petugas kesehatan untuk memelihara kehamilannya yang dilakukan sesuai standar pelayanan antenantal yang ditetapkan dalam standar pelayanan kebidanan. Tujuan pelayanan antenatal adalah mengantarkan ibu hamil agar dapat bersalin dengan sehat dan memperoleh bayi yang sehat, mendeteksi dan mengantisipasi dini kelainan kehamilan dan deteksi serta antisipasi dini 
kelainan janin (Depkes Republik Indonesia, 2012).

Permintaan masyarakat terhadap peran aktif bidan dari tahun ke tahun dalam memberikan pelayanan terus meningkat. Ini merupakan bukti bahwa eksistensi bidan di tengah masyarakat semakin memperoleh kepercayaan, pengakuan dan penghargaan. Berdasarkan hal inilah, bidan dituntut untuk selalu berusaha meningkatkan kemampuan sekaligus mempertahankan dan meningkatkan kualitas pelayananya termasuk ANC. Karena hanya melalui pelayanan berkualitas, pelayanan terbaik dan terjangkau yang diberikan oleh Bidan, maka kepuasan pelanggan baik kepada individu, keluarga dan masyarakat dapat tercapai (Pengurus Pusat Ikatan Bidan Indonesia, 2007).

Kepatuhan bidan menerapkan standar pelayanan kebidanan bagi kesehatan ibu dan anak berdampak dan mempunyai daya ungkit terhadap kualitas pelayanan antenatal yang diberikan, yang selanjutnya berkontribusi terhadap penurunan angka morbiditas dan mortalitas pada ibu dan bayi. Terdapat cukup bukti yang menunjukkan masih rendahnya kualitas pelayanan kesehatan di tingkat masyarakat, seperti studi yang dilakukan di Indonesia oleh D'Ambruoso, dkk, (2009) yang menyatakan bahwa pelayanan kebidanan yang diberikan oleh bidan masih di bawah standar pelayanan. Penelitian Prual,et.all di Nigeria (2005) menyebutkan kualitas pemeriksaan faktor risiko selama konsultasi antenatal memiliki efektifitas dalam mencegah dan memprediksi komplikasi obstetrik. Didukung penelitian Mathole,et.all di Zimbabwe (2011) menyatakan kunjungan antenatal yang pertama kali dapat mendeteksi komplikasi kehamilan.

Rendahnya kinerja bidan dapat disebabkan oleh beberapa hal, diantaranya adalah motivasi bidan sendiri, bidan melakukan pemeriksaan ANC dengan tergesa-gesa karena adanya pasien lain yang akan memeriksakan kesehatan, juga karena malas. Penelitian sebelumnya menyatakan bahwa, motivasi berhubungan erat dengan kinerja bidan dalam pelayanan ANC berdasarkan Standar Pelayanan Kebidanan (Umar, 2007). Motivasi dapat digunakan sebagai strategi untuk meningkatkan kinerja pegawai
Puskesmas, sebab efektivitas kinerja pegawai tergantung pada motivasinya (Sesri, 2008).

Motivasi adalah karakteristik psikologis manusia yang memberi kontribusi pada tingkat komitmen seseorang. Menurut Notoatmodjo (2007), motivasi adalah pemberian daya penggerak yang menciptakan kegairahan seseorang, agar mereka mau berbuat, bekerja efektif, dan terintegrasi dengan segala daya upaya untuk mencapai kepuasan. Dalam hal pelayanan kesehatan pada ibu hamil seorang bidan harus memiliki motivasi yang tinggi sehingga timbul semangat dalam bekerja.

Kompetensi bidan di desa terhadap standar ANC dapat dijelaskan berdasarkan variabel individu yang meliputi kemampuan, keterampilan, latar belakang, demografi; variabel psikologis yang meliputi persepsi, sikap, kepribadian, motivasi; dan variabel organisasi yang meliputi sumber daya, kepemimpinan, imbalan, struktur, desain pekerjaan, supervisi, dan kontrol. Studi di China mendapatkan tingkat kepatuhan dalam menerapkan standar tindakan pencegahan oleh perawat masih rendah $(48,29 \%)$ dan faktor yang berpengaruh adalah pelatihan, pengetahuan, pengawasan, kelas rumah sakit, pengalaman, dan unit kerja (Depkes. RI, 2013).

Dinas Kesehatan Kabupaten Tegal sejak tahun 2010 telah melaksanakan kegiatan supervisi fasilitatif oleh Bikor puskesmas terhadap Bidan Praktek Mandiri (BPM) yang diawali dengan sosialisasi dalam bentuk pemberian daftar tilik yang digunakan untuk penilaian dalam pelaksanaan supervisi fasilitatif terhadap BPM kepada 37 Bikor puskesmas yang ada di wilayah Dinas Kesehatan. Pelaksanaan supervisi fasilitatif Bikor terhadap BPM sampai saat ini belum berjalan dengan baik dan tidak berkesinambungan. Hasil yang diharapkan dari supervisi fasilitatif adalah jaminan terhadap berjalannya perbaikan mutu. Klasifikasi kepada dua BPM yang di supervisi bahwa supervisi fasilitatif masih dilakukan seperti supervisisupervisi sebelumnya tidak mendetail, waktunya singkat dan hanya mengutamakan ada bukti supervisi dari BPM.

Pelayanan kebidanan diberikan secara holistik yaitu memperhatikan aspek biopsikososio-budaya sesuai dengan harapan kebutuhan pasien. Pelayanan tersebut diberikan demi 
kelangsungan hidup dan pelayanan. Adapun faktor yang mempengaruhi kualitas pelayanan antara lain supervisi yang memfasilitasi serta terpenuhinya hak ibu hamil untuk memperoleh informasi melalui konseling, sehingga pelayanan yang dibutuhkan pasien dari penyedia layanan (provider) memiliki karakteristik antara lain semangat untuk melayani, nyaman, privasi, alami dan tepat (Zulvandi, 2014).

Motivasi kerja bidan akan berdampak pada mutu pelayanan ANC yang akan dilakukan oleh tenaga kesehatan, secara profesional akan memberikan pelayanan sebaik mungkin agar ibu hamil merasa puas atas pelayanan yang diberikan. Banyak faktor yang dapat mempengaruhi seseorang merasa puas atas pelayanan di suatu tempat, termasuk di RB seperti pengalaman bidan selama proses pemeriksaan, fasilitas yang lengkap, kemudahan lokasi RB yang mudah dijangkau, tarif yang kompetitif, kecepatan dalam melakukan pemeriksaan keramahan bidan dalam pelayanan ANC dan persalinan.

Berdasarkan hasil studi pendahuluan di Puskesmas Pagiyanten, dengan cara wawacara pada bidan koordinator, bahwa proses sosialisasi pelayanan antenatal terpadu sudah dilakukan dan telah dilakukan pelatihan. Hasil observasi berdasarkan buku Kesehatan Ibu dan Anak (KIA) yang dilakukan pada $30 \mathrm{ibu}$ hamil trimester III yang dilakukan di BPM wilayah Puskesmas Pagiyanten. Hasil observasi yang dilakukan adalah standar pelayanan antenatal terpadu belum semua dilaksanakan secara optimal. Pada BPM di wilayah Puskesmas Pagiyanten, ditemukan dokumentasi yang paling lemah (lebih dari 50\%) 1) tidak mendokumentasikan pemeriksaan Lingkar Lengan Atas (LILA) dan 2) tidak diberikan imunisasi TT dan 3) pemeriksaan Tinggi Fundus Uteri (TFU) secara metline. Adapun motivasi bidan dalam melakukan pelayanan ANC masih kurang baik, hal ini terbukti dengan masih adanya pelayanan ANC yang belum dilakukan dikarenakan banyaknya pasien yang melakukan pemeriksaan kesehatan sehingga memeriksa ANC dilakukan secara singkat dan dilakukan berdasarkan keluhan pasien serta banyaknya kegiatan adminstrasi yang harus dilakukan bidan keterkaitan akreditasi puskesmas sehingga berdampak pada motivasi bidan yang kurang dalam memenuhi standar mutu pelayanan ANC. Hal ini berdampak pada kurang terdeteksinya angka kehamilan resiko tinggi sehingga secara tidak langsung menyumbang pada kejadian angka kematian ibu.

Penelitian ini bertujuan untuk memperoleh bukti empiris mengenai pengaruh supervisi bidan koordinator terhadap standar mutu pelayanan antenatal care dengan motivasi kerja sebagai variabel intervening pada bidan di Wilayah Puskesmas Pagiyanten Kabupaten Tegal

\section{Metode Penelitian}

Jenis penelitian penjelasan (explanatory research) karena bermaksud menjelaskan hubungan kausal antara variabel-variabel melalui pengujian hipotesis. Sumber data yang digunakan dalam penelitian ini meliputi data primer, yaitu data yang diperoleh dari responden melalui kuesioner yang telah dibuat sesuai dengan indikator penelitian dan juga berdasarka data sekunder. Populasi dari penelitian ini adalah bidan di wilayah puskesmas Pagiyanten yang berjumlah 48 orang. Teknik pengambilan sampel dengan menggunakan metode total sampling yaitu teknik sampling yang dilakukan dengan mengambil semua populasi yang berjumlah 48responden.

Metode pengumpulan data yang digunakan dalam penelitian ini adalah menggunakan kuisioner. Skala yang digunakan untuk mengukur indikator-indikator variabel dalam kuisioner adalah Skala Likert. Analisis data menggunakan regresi linier berganda setelah terlebih dahulu dilakukan uji asumsi klasik dan uji kelayakan model.

\section{Hasil dan Pembahasan a. \\ Uji Validitas Validitas}

Uji validitas menggunakan koefisien korelasi Product Momen Pearson. Butir kuesioner dinyatakan sahih atau valid, jika $R_{\text {hitung }}$

$>\mathrm{R}_{\text {tabel}}$, uji validitas dilakukan pada 48 responden di luar responden penelitian, sehingga didapatkan $\mathrm{R}_{\text {tabel }}$ adalah 0,284 . Hasil uji validitas yang dilakukan dengan menggunakan program SPSS 17, maka kuesioner tentang supervisi bidan koordinator (X1), Motivasi kerja (M) dan standar mutu pelayanan $(\mathrm{Y})$ dinyatakan valid karena 
$\mathrm{R}_{\text {hitung }}$ masing-masing butir kuesioner diatas nilai $\mathrm{R}_{\text {Tabel }}, 0,284$.

\section{b. Reliabilitas}

Tabel 1 Reliabilitas

\begin{tabular}{|l|l|}
\hline Variabel & Alpha \\
\hline Supervisi bidan koordinator(X1) & 0,767 \\
\hline Motivasi kerja (M) & 0,908 \\
\hline Standar Mutu Pelayanan ANC (Y) & 0,902 \\
\hline
\end{tabular}

Dari kelima variabel nilai $\mathrm{r}$ alpha yang dihasilkan bernilai positif dan lebih besar dari 0,06 . Hasil keseluruhan instrumen penelitian ini handal.

\section{c. Pengujian Persyaratan Analisis}

1) Uji Normalitas Normal P-P Plot of Regression Standardized

Dependent Variable: Mutu pelayanan ANC

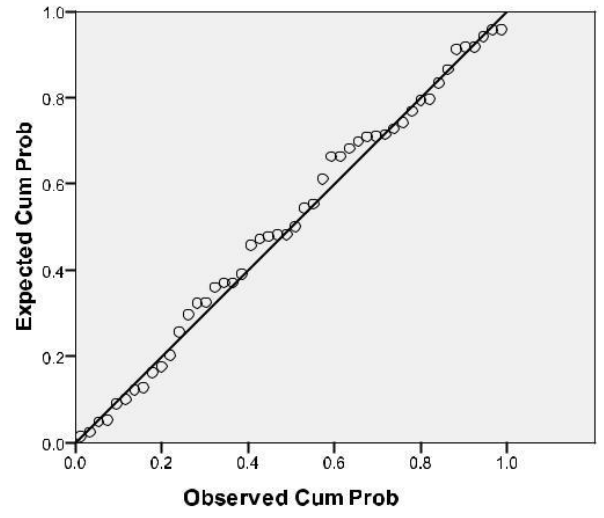

Gambar 1. Normalitas Data

Berdasarkan gambar di atas dapat diketahui bahwa penyebaran data (titik) pada Normal PPlot of Regression Standardized dari variabel terikat menyebar di sekitar garis diagonal, maka model regresi memenuhi asumsi normalitas.

2) Uji Multikoliniaritas

Tabel 2 Hasil Uji Multikolinier

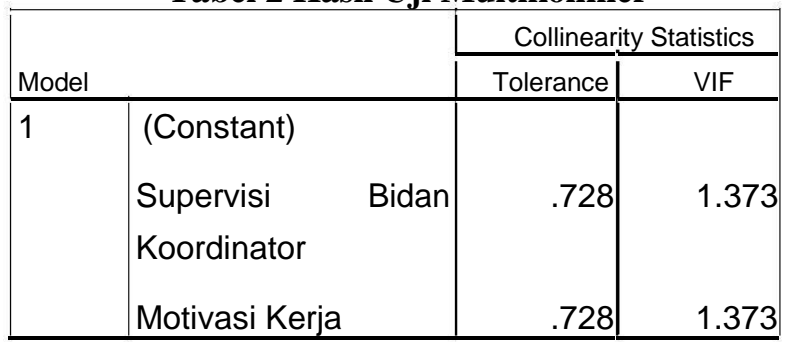

Hasil uji multikolinearitas pada pada tabel di atas diketahui bahwa hasil tolerance pada masing-masing variabel lebih besar dari 0,1 , sedangkan nilai Varians Inflation Factor (VIF) lebih kecil dari 10. Sehingga model regresi dalam penelitian ini tidak ada masalah multikolinearitas.

3) Uji Heteroskedastisitas

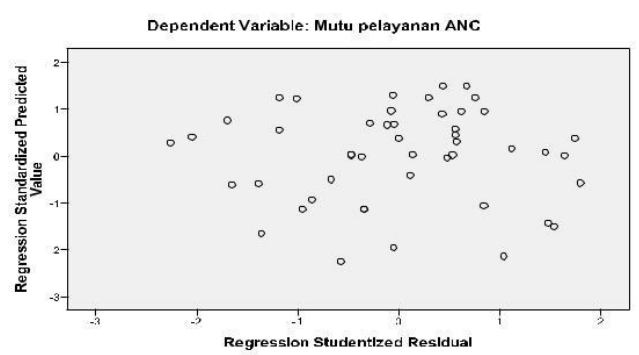

Gambar 2. Scatter Plot

Gambar di atas tidak menunjukkan adanya pola tertentu yang berarti tidak terjadi heterokodesitas dalam model regresi.

\section{d. Pengujian Hipotesis}

Tabel 3 Regresi I

Coefficients $^{a}$

\begin{tabular}{|c|c|c|c|c|c|}
\hline \multirow[b]{2}{*}{ Model } & \multicolumn{2}{|c|}{$\begin{array}{c}\text { Unstandardized } \\
\text { Coefficients }\end{array}$} & \multirow{2}{*}{$\begin{array}{c}\begin{array}{c}\text { Standardized } \\
\text { Coefficients }\end{array} \\
\text { Beta } \\
\end{array}$} & \multirow[b]{2}{*}{$\mathrm{t}$} & \multirow[b]{2}{*}{ Sig. } \\
\hline & B & Std. Error & & & \\
\hline (Constant) & 23.325 & 6.566 & & 3.552 & .001 \\
\hline $\begin{array}{l}\text { Supervisi } \\
\text { Bidan } \\
\text { Koordinator }\end{array}$ & 1.131 & .273 & .521 & 4.144 & .000 \\
\hline
\end{tabular}

Analisis hasil supervisi bidan koordinator berpengaruh positif terhadap motivasi kerja bidan (H2), diperoleh nilai signifikansi sebesar $0.000>$ 0.05 (H2 diterima), maka supervisi bidan koordinator secara statistik mempunyai pengaruh positif terhadap motivasi kerja bidan di wilayah Puskesmas Pagiyaten Kabupaten Tegal.

Tabel 4 Regresi 2 Coefficients $^{\mathrm{a}}$

\begin{tabular}{|l|r|r|r|r|r|}
\hline & \multicolumn{2}{|c|}{$\begin{array}{c}\text { Unstandardized } \\
\text { Coefficients }\end{array}$} & $\begin{array}{c}\text { Standardized } \\
\text { Coefficients }\end{array}$ & & \\
\cline { 2 - 5 } Model & $\mathrm{B}$ & Std. Error & \multicolumn{1}{c|}{ Beta } & $\mathrm{t}$ & Sig. \\
\hline $1 \quad$ (Constant) & 67.612 & 12.632 & & 5.353 & .000 \\
$\quad \begin{array}{l}\text { Supervisi } \\
\text { Bidan } \\
\text { Koordinator } \\
\text { Motivasi } \\
\text { Kerja }\end{array}$ & 1.127 & .545 & .304 & 2.067 & .045 \\
\hline
\end{tabular}

a. Dependent Variable: Standar Mutu pelayanan ANC 
Analisis hasil berdasarkan tabel 4 adalah sebagai berikut:

1) Supervisi bidan koordinator berpengaruh positif terhadap mutu pelayanan ANC (H1), diperoleh nilai signifikansi sebesar $0.045<$ 0.05 (H1 diterima), maka supervisi bidan koordinator secara statistik mempunyai pengaruh positif terhadap standar mutu pelayanan ANC.

2) Motivasi kerja berpengaruh positif terhadap mutu pelayanan ANC (H3), diperoleh nilai signifikansi sebesar $0.040<0.05$ (H3 diterima), maka motivasi kerja secara statistik mempunyai pengaruh positif terhadap standar mutu pelayanan ANC.

\section{Path Analysis}

Uji Path analysis digunakan untuk membuktikan apakah variabel komitmen kerja menjadi variabel yang memediasi antara motivasi, kompetensi dan kepuasan terhadap kinerja kader kesehatan. Analisis dilakukan berdasarkan dari nilai standardized coefficients dari hasil regresi dan dapat dibuat analisis jalur sebagai berikut :

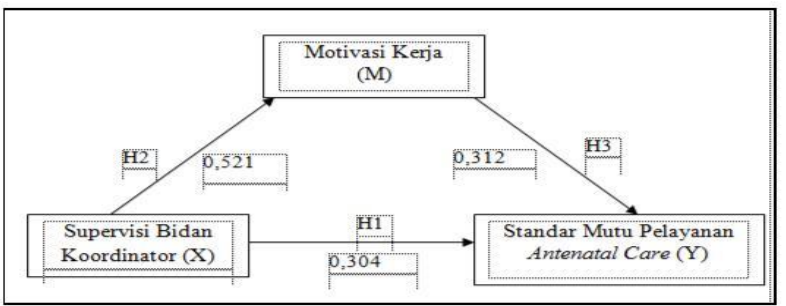

Gambar 3. Analisis Path

Berdasarkan dari gambar analisis jalur maka dapat dianalisis jalur Supervisi bidan koordinator terhadap standar mutu pelayanan ANC melalui motivasi kerja adalah sebagai berikut:

1. Pengaruh langsung supervisi bidan koordinator terhadap standar mutu pelayanan ANC sebesar 0,304.

2. Pengaruh supervisi bidan koordinator terhadap motivasi kerja sebesar 0,521 dan pengaruh motivasi kerja terhadap mutu pelayanan ANC sebesar 0,312 dengan demikian pengaruh tidak langsung Supervisi bidan koordinator terhadap mutu pelayanan ANC melalui motivasi kerja adalah sebesar $0,521 \times 0,312=0,162$
Hasil perhitungan menunjukkan pengaruh tidak langsung Supervisi bidan koordinator terhadap mutu pelayanan ANC melalui motivasi kerja lebih kecil dibanding pengaruh langsung Supervisi bidan koordinato terhadap mutu pelayanan ANC, sehingga dapat disimpulkan pengaruh langsung supervisi bidan koordinator terhadap standar mutu pelayanan ANC pada bidan lebih baik dibandingkan dengan pengaruh supervisi bidan koordinator terhadap standar mutu pelayanan ANC melalui motivasi kerja pada bidan di wilayah Puskermas Pagiyanten Kabupaten Tegal.

Analisis sobel digunakan untuk mengetahui pengaruh variabel mediator yaitu kepuasan kerja. Pengujian hipotesis mediasi dapat dilakukan dengan prosedur yang dikembangkan oleh Sobel (1982) dan dikenal dengan Uji Sobel (Sobel Test). Uji Sobel ini dilakukan dengan cara menguji kekuatan pengaruh tidak langsung variabel independent (X) kepada variabel dependent (Y) melalui variabel intervening (M). Pengaruh tidak langsung $\mathrm{X}$ ke $\mathrm{M}$ melalui $\mathrm{Y}$ dihitung dengan cara mengalikan jalur $\mathrm{X} \rightarrow \mathrm{M}$ (a) dengan jalur $\mathrm{M} \rightarrow \mathrm{Y}(\mathrm{b})$ atau ab.

Diketahui a

$=0,521 \mathrm{~b}=$

$0,312 \mathrm{ab}=$

$0,162 \mathrm{Sa}=$

$0,273 \mathrm{Sb}=$

0,251 maka

$$
\begin{aligned}
& =\longdiv { + } \\
& =\begin{array}{llllll}
0,521 & 0,251 & +0,312 & 0,273 & +0,273 & 0,251
\end{array}
\end{aligned}
$$

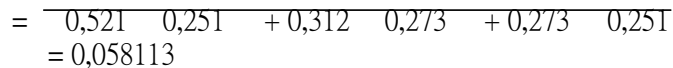

$$
\begin{aligned}
& =0,241
\end{aligned}
$$

Untuk menguji signifikansi pengaruh tidak langsung maka menitung nilai $t$ dari koefisien ab dengan rumus sebagai berikut:

Berdasarkan nilai thitung 0,672 dan setelah dibandingkan dengan $t_{\text {tabel }} 2,010$ maka thitung $0,672<\mathrm{t}_{\text {tabel }} 2,010$ dapat disimpulkan bahwa tidak ada pengaruh tidak langsung supervisi bidan koordinator terhadap standar mutu 
pelayanan antenatal care dengan motivasi kerja sebagai variabel intervening pada bidan di wilayah Puskesmas Pagiyanten Kabupaten Tegal.

\section{PEMBAHASAN}

Pengaruh supervisi bidan koordinator terhadap standar mutu pelayanan ANC

Berdasarkan hasil penelitian menunjukkan bahwa supervisi bidan koordinator berpengaruh positif terhadap mutu pelayanan ANC (pvalue $0.045<0.05)$, hal ini didukung dengan hasil kuesioner dari variabel supervisi bidan koordinator yang menujukkan bahwa sebanyak 19 responden $(39,6 \%)$ memberikan jawaban dengan kategori sedang artinya sebagian besar terlihat persepsi yang baik bahwa supervisor atau bidan koordinator memberikan kesempatan kepada bidan untuk menyampaikan

permasalahan yang dihadapi dalam penatalaksanaan ANC. Kegiatan supervisi yang dilakukan Bidan Koordinator sangat penting untuk menjamin pelaksanaan berbagai kegiatan yang telah direncanakan sehingga tujuan yang telah ditetapkan organisasi dapat dicapai dengan memuaskan.

Supervisi yang dilaksanakan oleh bidan koordinator KIA dengan memantau kelengkapan alat partus, alat pemeriksaan ibu hamil, alat pemeriksaan bayi, alat cek labroratorium

sederhana, kelengkapan obat-obatan, kelengkapan laporan PWS-KIA, kelengkapan register kohort ibu dan bayi, kelengkapan laporan imunisasi, kelengkapan status ibu dan bayi, kelengkapan partograf dan register persalinan, kelengkapan status KB, kelengkapan formulir surat keterangan lahir, surat keterangan kematian ibu dan bayi dan formulir rujukan. Bentuk sanksi yang diberikan dari pelaksanaan supervise terhadap temuan-temuan tentang ketidakpatuhan bidan dalam melakukan ANC yaitu berupa teguran lisan sebanyak $3 \mathrm{x}$, dilanjutkan dengan Surat Peringatan (SP 1) hingga yang terberat berupa Surat Pemecatan (atau yang dikenal dengan SP 3) bila sudah tidak dapat dilakukan tindakan pembinaan kepada individu yang bersangkutan (Dinkes Kab. Tegal, 2016).

Supervisi sangat penting bagi bidan untuk mendorong penatalaksanaan ANC sesuai dengan standar yang telah ditetapkan, karena dengan supervisi lebih membuat termotivasi bidan untuk melakukan pelayanan kesehatan yang lebih baik. Fungsi supervisi ini sangat penting di pelayanan kebidanan mengingat bidan bekerja dengan tujuan memenuhi kebutuhan masyarakat termasuk dalam hal penatalaksanaan ANC. Sedangkan tujuan supervisi adalah menilai pelaksanaan kerja apakah sesuai dengan perencanaan, memeriksa hasil kerja, dan meningkatkan kinerja (Muchlas M, 2007).

Hasil penelitian ini sesuai dengan penelitian Subekti (2012) meneliti bahwa pengetahuan, motivasi, supervisi dan imbalan berhubungan dengan kinerja. Sulistyaningsih (2011) juga berpendapat bahwa supervisi yang paling berpengaruh yaitu supervisi dengan kinerja bidan Desa di Kabupaten Pati. Subvariabel dari supervisi dalam penelitian ini, diukur dengan indikator pelaksanaan supervisi yang dilakukan oleh bidan koordinator KIA di wilayah puskesmas bidan desa meliputi keteraturan pelaksanaan supervisi, indikator dalam pelaksanaan supervisi (kelengkapan sarana dan prasarana \& kelengkapan pencatatan dan pelaporan), hasil supervisi telah disampaikan kepada bidan desa. Hal ini juga didukung penelitian oleh Kurniawati (2011), bahwa kinerja bidan desa dipengaruhi oleh faktor organisasi yaitu supervisi oleh bidan koordinator di Kabupaten Banyumas.

\section{Pengaruh supervisi bidan koordinator terhadap motivasi kerja}

Berdasarkan hasil penelitian menunjukkan bahwa supervisi bidan koordinator berpengaruh positif terhadap motivasi kerja (pvalue $0.000<$ 0.05), hal ini berarti bahwa supervisi bidan koordinator yang tinggi berdampak pada motivasi kerja bidan yang tinggi pula, kegiatan supervisi yang dilakukan Bidan Koordinator yang dilakukan untuk menjamin pelaksanaan ANC sesuai standar mutu pelayanan akan memacu motivasi bidan dalam melakukan pemeriksaan ANC. Hasil penelitian menunjukkan bahwa motivasi kerja bidan dalam kategori sangat tinggi $(52,1 \%)$ yang berarti bahwa sebagian besar responden mempunyai semangat bekerja dengan baik, meningkatkan segala kemampuannya untuk mewujudkan 
tujuan organisasi sehingga berhasil mencapai dan mewujudkan tujuan yang telah ditentukan terutama dalam hal pelaksanaan ANC.

Berdasarkan jawaban dari pertanyaan supervisi, sebagain besar responden menginginkan bahwa kegiatan supervisi oleh bidan koordinator tidak dilakukan secara mendadak, tetapi dilakukan pemberitahuan terlebih dahulu dan supervisor akan membuat alternative pemecahan masalah dalam penatalaksanaan ANC sehingga berdampak pada penatalaksaan yang baik. Ada empat faktor besar manfaat dari supervisi, yaitu untuk membuat yakin bahwa sasaran program adalah tepat, dapat mengatasi kesulitan yang dihadapi, dapat meningkatkan motivasi staf, dan dapat membantu meningkatkan penampilan petugas serta kemampuannya.

Motivasi kerja yang merupakan suatu dorongan jiwa yang membuat seseorang pekerja tergerak untuk melakukan tindakan yang produktif, dorongan yang kuat dalam diri luar individu karena merupakan salah satu usaha untuk melakukan kegiatan yang mengarah pada tujuan pelaksanaan ANC secara bermutu sesuai standar mutu pelayanan ANC yaitu ditunjukkan dengan adanya sikap bidan dalam menjalankan pelayanan ANC pada ibu hamil sesuai dengan standar yang telah ditentukan (Sarworini, 2014).

Hasil penelitian ini sesuai dengan hasil penelitian terdahulu yang dilakukan Wardani (2015), Yuyuk Liana (2014) dan Putri (2015) yang menemukan bahwa supervisi berpengaruh terhadap motivasi kerja karyawan, dengan supervisi yang tinggi berdampak pada semakin baik motivasi kerja.

\section{Pengaruh motivasi kerja terhadap standar mutu pelayanan antenatal care}

Berdasarkan hasil penelitian menunjukkan bahwa motivasi kerja berpengaruh positif terhadap standar mutu pelayanan ANC (pvalue $0.040<0.05$ ) yang berarti bahwa semakin tinggi motivasi kerja bidan maka mutu pelayanan akan baik, karena motivasi kerja merupakan proses pemberian motif (penggerak) bekerja kepada para pegawai sehingga mereka mau bekerja demi tercapainya tujuan perusahaan secara efektif dan efisien.
Berdasarkan respon dari responden menunjukkan bahwa mutu pelayanan ANC dalam kategori tinggi yaitu dengan frekuensi 13 responden $(27,1 \%)$, artinya mutu pelayanan bidan dalam pelaksanaan ANC sudah baik, bidan dalam melakukan ANC menurut standar ANC dengan melakukan $10 \mathrm{~T}$, serta sebelum pelaksanaan ANC dilakukan registrasi serta anamnesa terlebih dahulu, dan bidan memberikan konseling pada ibu hamil sesuai dengan umur kehamilan serta kebutuhan yang dapat menghambat kehamilan juga bidan

melakukan pendokumentasian asuhan pelaksanaan ANC pada buku KIA yang dibawa oleh ibu hamil.

Pemberian motif kerja ini terdapat dalam teori kebutuhan hierarki Maslow yang meliputi kebutuhan fisiologis, kebutuhan keamanan, kebutuhan sosial, kebutuhan penghargaan dan kebutuhan aktualisasi diri. Dengan terpenuhinya semua kebutuhan atau keinginan dan harapan maka pegawai akan mendapatkan kepuasan, dan pegawai yang tingkat kepuasannya tinggi maka secara otomatis kinerja akan meningkat. Ada beberapa hal yang menghubungkan antara kepuasaan kerja dengan kinerja pegawai, terutama reward. Dalam hal ini bila pegawai menerima penghargaan yang mereka anggap pantas mendapatkannya, dan puas, pegawai tersebut dapat menghasilkan kinerja yang lebih besar (Handoko, 2009).

Hasil penelitian ini sesuai dengan hasil penelitian terdahulu yang dilakukan Koesmono (2005), Ayu dan Suprayetno (2008) serta Harry Murti (2013) yang menemukan bahwa motivasi berpengaruh signifikan terhadap kinerja pegawai, semakin tinggi atau positif motivasi kerja pegawai maka berdampak pada semakin tinggi kinerja pegawai.

\section{Motivasi kerja sebagai variabel intervening pengaruh supervisi bidan koordinator terhadap standar mutu pelayanan antenatal care}

Hasil perhitungan penelitian dengan analisis Sobel menunjukkan bahwa supervisi bidan koordinator tidak mempunyai pengaruh tidak langsung terhadap standar mutu pelayanan ANC melalui motivasi kerja pada bidan di wilayah Puskermas Pagiyanten Kabupaten 
Tegal. Kegiatan supervisi yang dilakukan Bidan Koordinator sangat penting untuk menjamin pelaksanaan berbagai kegiatan yang telah direncanakan sehingga tujuan yang telah ditetapkan organisasi dapat dicapai dengan memuaskan. Hal ini berarti bahwa supervisi bidan koordinator berpengaruh secara langsung terhadap standar mutu pelayanan ANC dibandingkan mellaui motivasi kerja bidan. Kegiatan supervisi yang dilakukan Bidan Koordinator berdampak pada kepatuhan bidan dalam pelaksanaan ANC sesuai standar mutu pelayanan ANC.

Kepatuhan bidan dalam menerapkan standar ANC merupakan bentuk perubahan perilaku bidan dalam memberikan pelayanan kebidanan secara optimal yang selanjutnya berdampak pada upaya penurunan morbiditas dan mortalitas maternal serta neonatal. Kepatuhan bidan akan langgeng kalau muncul dari motivasi bidan itu sendiri karena supervisi bidan koordinator hanya dilakukan secara berkala.

Peran bidan koordinator diharapkan dapat mengaplikasikan teknik, keterampilan dan pengetahuan termasuk teori motivasi untuk membantu bidan dalam menerapkan standar praktik ANC. Untuk menghasilkan pembinaan yang baik, diperlukan interaksi yang fasilitatif dan produktif serta harmonis antara Pembina dan yang dibina. Dengan dasar interaksi yang baik inilah kemudian direncanakan strategi pembinaan yang mantap dan terarah. Pembinaan yang efektif akan menghasilkan tenaga yang ber-etika, terampil, efiien dan tangguh. Kualitas tenaga bidan yang demikian akan mempunyai dampak dalam mempercepat penurunan angka kematian ibu, bayi baru lahir, bayi dan anak balita.

Hasil penelitian ini tidak sejalan dengan Yuliana Nurbaeti (2010) yang menyatakan bahwa ada perbedaan kepatuhan menerapkan standar antara petugas yang mendapat supevisi dengan baik dan petugas yang tidak disupervisi dengan baik. Hal tersebut relevan juga dengan hasil penelitian Guspianto (2007) bahwa supervisi dan motivasi berhubungan dengan kepatuhan bidan di desa terhadap standar layanan antenatal care.

\section{Kesimpulan}

Berdasarkan hasil penelitian dan pembahasan yang telah dilakukan, maka kesimpulan yang dapat diambil adalah sebagai berikut 1) Supervisi bidan koordinator mempunyai pengaruh positif terhadap mutu pelayanan ANC pada bidan di Wilayah Puskesmas Pagiyanten Kabupaten Tegal ( $p$ value $0.045>0.05)$. 2) Supervisi bidan koordinator mempunyai pengaruh positif terhadap motivasi kerja pada bidan di Wilayah Puskesmas Pagiyanten Kabupaten Tegal ( $p$ value 0.000 >0.05). 3) Motivasi kerja mempunyai pengaruh positif terhadap mutu pelayanan ANC pada bidan di Wilayah Puskesmas Pagiyanten Kabupaten Tegal ( $p$ value $0.040>$ 0.05) dan 4) Supervisi bidan koordinator tidak berpengaruh secara tidak langsung terhadap mutu pelayanan antenatal care dengan motivasi sebagai variabel intervening pada bidan di Wilayah Puskesmas Pagiyanten Kabupaten Tegal.

\section{Saran}

Penelitian ini diharapkan dapat memberikan berbagai manfaat bagi kepala Puskesmas, bahwa dalam rangka menciptakan kinerja kader kesehatan maka harus memperkuat motivasi dan kompetensi kader kesehatan tertutama pada kompetensi pengetahuan, sikap dan keterampilan kader, dengan cara melalui pendidikan dan pelatihan serta menciptakan kinerja kader kesehatan yang tinggi.

\section{DAFTAR PUSTAKA}

Ayu dan Suprayetno. 2008. Pengaruh Motivasi Kerja,. Kepemimpinan dan Budaya Organisasi Terhadap Kepuasan Kerja. Karyawan serta Dampaknya pada Kinerja Perusahaan, Jurnal Manajemen dan Kewirausahaan, Vol 10 No. 2:124-135.

D'Ambruoso, dkk. 2009. Confidential Inquiries Into Maternal Death: Modifications and. Adaption in Ghana and Indonesia. Journal of Gynecology and Obstetrics Volume 106:80-. 84. July 2009

Depkes Republik Indonesia, 2012. Profil Kesehatan Indonesia 2011. Jakarta: Depkes RI 
Depkes RI, 2016. Profil Kesehatan Indonesia tahun 2016. Jakarta: Depkes RI

Depkes RI, 2017. Profil Kesehatan Indonesia tahun 2017. Jakarta: Depkes RI

Depkes RI. 2016. Dinkes Jateng (2016), Dinkes Kab. Tegal (2016)

Depkes. RI, 2013. Riset Kesehatan Dasar (Riskesdas) 2013. Jakarta: Depkes RI.

Dinkes Kabupaten Tegal, 2016. Profil Kesehatan Kabupaten Tegal 2015. Tegal; dinkes Tegal.

Guspianto. 2007. Determinan Kepatuhan Bidan di Desa terhadap Standar. Antenatal Care. Jurnal Kesehatan Masyarakat Nasional Vol. 7, No. 2,. September 2012.

Handoko, 2009. Manajemen, Cetakan Duapuluh, Yogyakarta : Penerbit. BPEE

Harry Murti. 2013. Pengaruh Motivasi. Terhadap Kinerja Pegawai Dengan Variabel Pemediasi Kepuasaan. Kerja Pada PDAM Kota Madiun. Jurnal Riset Manajemen dan. Akuntansi (JRMA). Vol. 1 No. 1, Februari 2013. pp

Koesmono.2005. Pengaruh Budaya Organisasi terhadap Motivasi dan Kepuasan Kinerja Karyawan pada sub sektor Industri pengolahan kayu skala menengah di Jawa Timur, Jurnal Manajemen \&. Kewirausahaan, Vol.7, No.2. Surabaya: Universitas Kristen Petra.

Kurniawati, 2012. Buku Ajar Kependudukan dan Pelayanan. KB. Jakarta: EGC

Melinda. 2013. Manajemen Sumber Daya Manusia : Untuk Bisnis Yang Kompetitif, GMUP: Yogyakarta

Muchlas M, 2007. Perilaku Organisasi. Yogyakarta: Gadjah Mada University Press.

Notoatmodjo, 2007. Pendidikan dan Ilmu Perilaku. Jakarta: PT Rineka Cipta

Pengurus Pusat Ikatan Bidan Indonesia, 2007. Catatan Konsep Kebidanan Plus Materi Bidan. Delima, Yogyakarta, Mitra Cendikia

Prual et.al. 2011. Effctieness of External Inspection of Compliance with Standards in Improving Healthcare Organization Behavior and Healthcare Profesional Behavior. Department of Publish Health, University of Oxford.
Putri. 2015. Analisis Pengaruh Persepsi, Sikap, Pengetahuan dan Tempat Kerja terhadap Perilaku Keselamatan Karyawan (Studi pada. Perusahaan PT MuliaGlass Container Division). Skripsi. Fakultas. Ekonomika dan Bisnis Undip

Ridwan, 2012. Skala Pengukuran Variabelvariabel Penelitian. Bandung : Alfabeta

Sesri, 2008. Faktor-faktor yang Berhubungan dengan Kinerja Petugas KIA Puskesmas Pembantu dalam Pelayanan Antenatal di Kabupaten Agam. Tesis Program Pasca Sarjana FKM-UI. Depok.

Subekti. 2012. Pengaruh Pengembangan Sumber

Daya Manusia Terhadap Kinerja Pegawai

(Studi Kasus Pada Dinas Perhubungan

Kota Medan)

Sulistyaningsih. 2011. Metodologi Penelitian

Kuantitatif dan Kualitatif. Yogyakarta :

Graha Ilmu.

Umar, 2007. Faktor-faktor yang Berhubungan dengan Kinerja Bidan di Desa dalam Pelayanan ANC berdasarkan Standar Pelayanan Kebidanan di Kabupaten Batag Hari Propinsi Jambi Tahun 2007. Tesis Program Pasca Sarjana FKM-UI. Depok.

Wardani (2015), nalisis Faktorfaktor yang Mempengaruhi Kepatuhan Bidan dalam penatalaksaan asuhan kebidanan di Ruang Rawat Inap RS Mardi Rahayu Kudus. Magister Ilmu Kesehatan Masyarakat Undip Semarang (Tesis).

Yuliana Nurbaeti. 2010. Motivasi dan Pemotivasian. Jakarta: Penerbit Raja Grafindo Persada

YuyukLiana. 2014. Ilkim Organisasi dan Motivasi Berprestasi Terhadap. Kepuasan Kerja dan Kinerja Guru. Jurnal Manajemen dan Akuntansi vol. 1,. No.2.

Zulvandi, 2014. Hubungan antara reward, komitmen dan motivasi perawat dengan pelaksanaan di RSUD Labuang Baji Makassar. Tesis. UnHas 